\title{
Zeolite from fly ash: synthesis and characterization
}

\author{
KEKA OJHA, NARAYAN C PRADHAN* and AMAR NATH SAMANTA \\ Department of Chemical Engineering, Indian Institute of Technology, Kharagpur 721 302, India
}

MS received 20 May 2004; revised 22 September 2004

\begin{abstract}
Coal fly ash was used to synthesize X-type zeolite by alkali fusion followed by hydrothermal treatment. The synthesized zeolite was characterized using various techniques such as $\mathrm{X}$-ray diffraction, scanning electron microscopy, Fourier transform infrared spectroscopy, BET method for surface area measurement etc. The synthesis conditions were optimized to obtain highly crystalline zeolite with maximum BET surface area. The maximum surface area of the product was found to be $383 \mathrm{~m}^{2} / \mathrm{g}$ with high purity. The crystallinity of the prepared zeolite was found to change with fusion temperature and a maximum value was obtained at $823 \mathrm{~K}$. The cost of synthesized zeolite was estimated to be almost one-fifth of that of commercial 13X zeolite available in the market.
\end{abstract}

Keywords. Fly ash; NaX zeolite; hydrothermal treatment; X-ray diffraction; scanning electron microscopy; BET surface area.

\section{Introduction}

The amount of coal fly ash generated by coal-based thermal power plants has been increasing at an alarming rate throughout the world. The disposal of such a huge quantity of ash has become a pressing issue. In India, more than 90 million tons of fly ash is being generated annually with more than 65,000 acres of land being occupied by ash ponds. Several approaches have been made for proper utilization of fly ash, either to reduce the cost of disposal or to minimize the environmental impact. One of the approaches is the conversion of fly ash to zeolites, which have wide applications in ion exchange, as molecular sieves, catalysts, and adsorbents (Breck 1974). The present study is concerned with the synthesis of zeolite from coal fly ash and its characterization using various techniques.

Fly ash is mainly composed of some oxides derived from inorganic compounds, which remain after combustion of the coal. The amounts of the main components of ash viz. $\mathrm{SiO}_{2}$ and $\mathrm{Al}_{2} \mathrm{O}_{3}$, show few variations with the type of coal. The similar chemical composition of fly ash and some volcanic rocks prompted several research groups to attempt making zeolite from fly ash (Höller and Wirsching 1985; Henmi 1987a; Mondragón et al 1990; Shigemoto et al 1992; Yang and Kirkpatrick 1990; Lin and Hsi 1995; Park and Choi 1995; Shin et al 1995). In general, zeolite synthesis processes involve the addition of a caustic agent to the fly ash slurry at higher temperatures. In 1985, Höller and Wirsching utilized fly ash as the raw material for synthesis of zeolite using hydrothermal method. After that, a number of researchers have used this process successfully, varying the hydrothermal tempera-

\footnotetext{
*Author for correspondence
}

ture within the range of 333-573 K (Henmi 1987a,b; Mondragón et al 1990; Yang and Kirkpatrick 1990; Shigemoto et al 1992; Lin and Hsi 1995; Park and Choi 1995; Shin et al 1995; Chang and Shih 1998). Henmi (1987a,b) synthesized hydroxy-sodalite by conventional hydrothermal process in the temperature range $353-363 \mathrm{~K}$ for $3-$ $24 \mathrm{~h}$. He succeeded in converting about $30 \%$ of the original fly ash to hydroxy-sodalite with high cation exchange capacity compared to the original fly ash. However, major attempts on zeolitization of fly ash have been made from 1990 onwards.

Mondragón et al (1990) investigated on possible uses of coal fly ash, in general and synthesis of zeolitic material from it, in particular. But like most other investigators, they also tried the hydrothermal method. Adsorption property of the treated fly ash was reported to be similar to that of commercial $13 \mathrm{X}$ zeolite. Shigemoto and co-workers (1992) also synthesized zeolite by using a similar method. They have developed fusion followed by hydrothermal treatment method to synthesize low silica NaXtype zeolite from fly ash (Shigemoto et al 1993). Fusion of the alkali-fly ash mixture facilitates the formation of highly active Na-aluminate and silicates, which are readily soluble in water and enhance zeolite formation. Using fusion followed by hydrothermal process, the investigators developed low silica, X-type zeolite selectively. Addition of sodium aluminate to the fly ash before fusion brought the success in obtaining $\mathrm{Na}-\mathrm{A}$ zeolite also.

Lin and Hsi (1995) extensively investigated effects of the hydrothermal reaction parameters such as temperatures, molarity of caustic reagents and reaction time on the properties of the treated fly ash and also optimized the reaction parameters to obtain best quality product. They carried out experiments in open as well as in closed systems at elevated pressure (500 psi) and temperatures 
as high as $473 \mathrm{~K}$. The synthesis of zeolite was also studied with fly ash of varying chemical composition, which was not investigated in previous works.

Shih and Chang (1996) investigated the effects of curing temperature and chemical composition on formation of two types of zeolites, zeolite A and faujasite, from Class F fly ash at lower temperature (only $311 \mathrm{~K}$ ). But, the treatment time required for synthesizing zeolite A by them was longer enough, more than 3 days. Yoshida and Inoue (1986) synthesized a similar type of zeolite A at $363 \mathrm{~K}$ and they observed that at higher temperature zeolite A began to disappear and zeolite P started to form.

Querol and co-workers (1997a) used $\mathrm{KOH}$ and $\mathrm{NaOH}$ as activators to synthesize zeolite using both open and closed system. They have carried out experiments from fly ashes of varying compositions, collected from different power plants. Their results have shown higher conversion efficiency of $\mathrm{NaOH}$ than that of $\mathrm{KOH}$ solutions; even at higher $\mathrm{KOH}$ concentrations (1.0 M and $473 \mathrm{~K})$, quartz and mullite could not be dissolved substantially and remained in the fly ash. Higher $\mathrm{pH}$ of the solution also showed better zeolite synthesis efficiency. Mainly zeolite NaP1, NaP derivatives and Phillipsites have been synthesized by $\mathrm{NaOH}$ and $\mathrm{KOH}$ activation.

Querol et al (1997b) reported microwave-assisted method for zeolite synthesis from coal fly ash. Yields and zeolite types obtained from the microwave and conventional experiments have been reported to be very similar, but the activation time has been drastically reduced by using microwaves (from $24-48 \mathrm{~h}$ to $30 \mathrm{~min}$ ).

Chang and Shih (1998) established the alkali fusion followed by hydrothermal treatment as a general method for synthesis of a particular type of zeolite from different sources of fly ash. They have also compared their results with simple hydrothermal treatment (without fusion) and have concluded that the fusion approach is a better process which can be applied to fly ash of wide composition ranges. In the year 2000 , the same research group published another paper (Chang and Shih 2000) in which they described fusion method to synthesize zeolites $\mathrm{X}, \mathrm{Y}$ and A. They also showed the capability of fusion method to synthesize a specific zeolite selectively by varying the reaction parameters.

Park and co-workers (2000) developed a new method for synthesizing zeolite under molten conditions without any addition of water. However, complete zeolitization of fly ash could not be accomplished by this molten salt method, probably due to low temperature and insufficient contact of $\mathrm{NaOH}$ with raw materials. The molten salt product was of irregular morphology, in which zeolites could not be identified by their characteristic morphological shapes. On the other hand, well-developed polycrystals were observed in the hydrothermal product. These results indicate that the crystal growth in molten-salt state is somewhat limited compared to that in hydrothermal products.

Based on the above discussion, it can be concluded that alkali fusion followed by hydrothermal treatment is the most reliable method of obtaining faujasite $(\mathrm{Na}-\mathrm{X}$ and $\mathrm{Na}-\mathrm{Y}$ ) type zeolite selectively from fly ash of different compositions. It was, therefore, thought desirable to convert fly ashes from some of the Indian thermal power plants to zeolites, which could be used as catalysts for some industrially important reactions, by alkali fusion followed by hydrothermal treatment.

\section{Experimental}

\subsection{Materials}

The main raw material, coal fly ash samples were collected from electrostatic precipitators of three different Indian thermal power plants, Kolaghat Thermal Power Station (KTPS) and Durgapur Thermal Power Station (DTPS), West Bengal and National Aluminium Company (NALCO), Orissa, India. The samples contained both amorphous (mainly $\mathrm{SiO}_{2}, \mathrm{Al}_{2} \mathrm{O}_{3}$ ) and crystalline components (mainly quartz and mullite). Table 1 presents the physico-chemical properties of the fly ash samples used in the pre-

Table 1. Physico-chemical properties of fly ash samples obtained from different Indian thermal power plants.

\begin{tabular}{lccc}
\hline & \multicolumn{3}{c}{ Composition (wt \%) of fly ash obtained from } \\
\cline { 2 - 4 } Components & \multicolumn{1}{c}{ KTPS } & DTPS & NALCO \\
\hline $\mathrm{Na}_{2} \mathrm{O}$ & $2 \cdot 12$ & $1 \cdot 14$ & $0 \cdot 70$ \\
$\mathrm{Al}_{2} \mathrm{O}_{3}$ & $30 \cdot 01$ & 27.86 & 29.19 \\
$\mathrm{SiO}_{2}$ & $55 \cdot 19$ & $60 \cdot 03$ & $55 \cdot 60$ \\
$\mathrm{~K}_{2} \mathrm{O}$ & 1.40 & 0.00 & 1.09 \\
$\mathrm{CaO}$ & 0.77 & 0.54 & 3.69 \\
$\mathrm{TiO}_{2}$ & 2.74 & 4.27 & 2.03 \\
$\mathrm{Fe}_{2} \mathrm{O}_{3}$ & 4.58 & 4.08 & 4.95 \\
$\mathrm{BaO}$ & 1.28 & $0 \cdot 21$ & 0.00 \\
$\mathrm{MgO}$ & 1.91 & 1.87 & 2.75 \\
$\mathrm{Surface}$ area $\left(m^{2} / \mathrm{g}\right)$ & 2.9 & 1.4 & 3.5 \\
Mean particle size $(\mu \mathrm{m})$ & 24.90 & 26.08 & 13.94 \\
\hline
\end{tabular}


sent investigation. As can be seen from this table, the fly ash samples used were of 'Class $\mathrm{F}$ ' type with $\mathrm{SiO}_{2}, \mathrm{Al}_{2} \mathrm{O}_{3}$ and iron oxide as the major constituents. Commercial $13 \mathrm{X}$ zeolite was purchased from SRL Pvt. Ltd., Mumbai, India. Sodium hydroxide was procured from Glaxo Laboratories (India) Ltd.

\subsection{Zeolite synthesis}

Before any treatment, the raw fly ash samples were first screened through a BSS Tyler sieve of 80-mesh size to eliminate the larger particles. The unburnt carbon (4-6\%) along with other volatile materials present in fly ash were removed by calcination at $800( \pm 10){ }^{\circ} \mathrm{C}$ for $2 \mathrm{~h}$. Fly ash samples were further treated with hydrochloric acid to increase their activity in zeolite formation. The acid treatment helped to dealuminate the fly ash and removed iron to a certain extent, thereby increasing the activity, thermal stability and acidity of the zeolite, all aiming for better catalytic applications.

Mixture of sodium hydroxide and fly ash (calcined and $\mathrm{HCl}$ treated) in a pre-determined ratio, was milled and fused in a stainless steel tray at different temperatures ranging from $500-650^{\circ} \mathrm{C}$ for $1 \mathrm{~h}$. The sodium hydroxide to fly ash ratio (by weight) was varied from $1 \cdot 0-1 \cdot 5$. The resultant fused mixture was then cooled to room temperature, ground further and added to water $(10 \mathrm{~g}$ fly ash $/ 100 \mathrm{ml}$ water). The slurry thus obtained was agitated mechanically in a glass beaker for several hours. It was then kept at around $90^{\circ} \mathrm{C}$ for $6 \mathrm{~h}$ without any disturbance. The flow diagram of the synthesis process is shown in figure 1 . The resultant precipitate was then repeatedly washed with distilled water to remove excess sodium hydroxide, filtered and dried. The sodium hydroxide added to the fly ash not only works as an activator, but also adjusts the sodium content in the starting material. Mullite and $\alpha$ quartz present in the fly ash are the sources of aluminum and silicon, respectively, for zeolite formation. The synthesis conditions used with different samples are presented in table 2 .

\subsection{Characterization}

2.3a X-ray diffraction: The X-ray (powder) diffraction (XRD) patterns of different fly ash samples and synthetic zeolitic materials were obtained using a Philips X-ray diffractometer (Philips BW1710). Operating conditions involved the use of $\operatorname{CoK} \alpha$ radiation at $4 \mathrm{kV}$ and $30 \mathrm{~mA}$. The samples were scanned from $10-50^{\circ}(2 \theta$, where $\theta$ is the angle of diffraction). Various crystalline phases present in the samples were identified with the help of JCPDS (Joint Committee on Powder Diffraction Standards) files for inorganic compounds. Quantitative measure of the crystallinity of the synthesized zeolite was made by using the summed heights of major peaks in the X-ray diffrac- tion pattern (Szostak 1976). The major peaks were selected specifically because they are least affected by the degree of hydration of samples and also by others. The percentage crystallinity was taken as the sum of the peak heights of the unknown materials divided by the sum of the peak heights of a standard material that has been assumed to be $100 \%$ crystalline i.e.

\section{$\%$ Crystallinity $=($ sum of the peak heights of unknown material) $\times 100 /$ (sum of peak heights of standard material).}

2.3b Morphological analysis by scanning electron microscope (SEM): The morphological structure of the raw fly ash, treated fly ash and synthesized zeolitic materials were obtained by using scanning electron micrograph (Jeol, JSM 5800). The bulk composition was also estimated from SEM/EDXS by indirect method. The elemental composition of the samples was first determined from the SEM/ EDXS, and from these data, the percentages of oxides

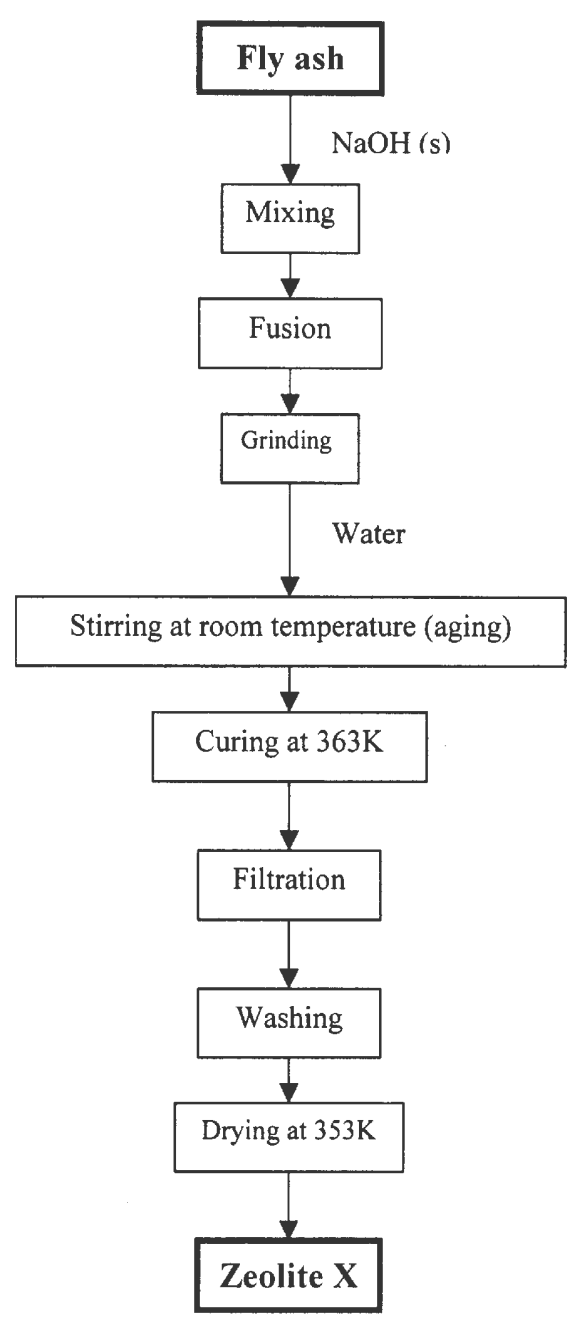

Figure 1. Process flow diagram for synthesis of zeolite from fly ash. 
Table 2. Zeolites designations and their synthesis conditions.

\begin{tabular}{lcccccc}
\hline & & \multicolumn{5}{c}{ Zeolite synthesis condition } \\
\cline { 3 - 5 } Zeolite & Source & NaOH/fly & Fusion & Aging & \multicolumn{2}{l}{ Hydrothermal treatment } \\
\cline { 6 - 7 } designation & of fly ash & ash ratio & temp (K) & time (h) & Temp (K) & Time (h) \\
\hline ZOP-21 & KTPS & $1 \cdot 2$ & 823 & 12 & 363 & 6 \\
ZOP-30 & KTPS & $1 \cdot 3$ & 823 & 24 & 363 & 6 \\
ZOP-31 & KTPS & $1 \cdot 3$ & 823 & 18 & 363 & 6 \\
ZOP-53 & DTPS & $1 \cdot 3$ & 823 & 18 & 363 & 6 \\
ZOP-57 & NALCO & $1 \cdot 3$ & 823 & 18 & 363 & 6 \\
\hline
\end{tabular}

KTPS: Kolaghat Thermal Power Station, West Bengal, India; DTPS: Durgapur Thermal Power Station, West Bengal, India; NALCO: National Aluminium Company Ltd., Orissa, India.

were calculated. The results were further verified by X-ray fluorescence (XRF) data.

2.3c Particle size and surface area: The average particle sizes of various samples were determined by particle size analyser (Malvern Instruments M7). BET method was used to measure specific surface area of the samples (Flowsorb-II, Micromeritics).

2.3d Fourier transform infrared (FT-IR) spectra: Infrared spectroscopic analysis of different materials was carried out to study their structural features and acidity. Infrared spectroscopic analysis of the prepared zeolite samples was performed with a Nicolet Magna (Series II) spectrometer with a DTGSBr detector and $\mathrm{KBr}$ as beam splitter with 100 scans for wave number range of 400 $4000 \mathrm{~cm}^{-1}$.

\section{Results and discussion}

\subsection{Mineralogical properties}

The coal fly ash contains mainly $\mathrm{SiO}_{2}, \mathrm{Al}_{2} \mathrm{O}_{3}$ and some amount of $\mathrm{Fe}_{2} \mathrm{O}_{3}$ and the oxides of $\mathrm{Mg}, \mathrm{Ca}, \mathrm{P}$, Ti etc. The chemical compositions of fly ash samples used in the present study are given in table 1 . The X-ray diffraction patterns of original fly ash, zeolite synthesized from fly ash (ZOP-30) and commercial 13X zeolite are shown in figure 2 . The XRD pattern of original fly ash mainly represents the presence of crystalline quartz and mullite. Besides some crystalline phases (quartz, mullite, hematite etc), ash is primarily composed of amorphous material. The partial hub seen in the background at lower diffraction angle is responsible for the amorphous phases. The full hub is not visible as the scanning was started from $10^{\circ}$ and not from the origin.

Fly ash, after treatment gives several sharp diffraction peaks, which are different from those present in the untreated one. Different crystalline zeolitic phases present in the treated fly ashes were identified using INORGANIC

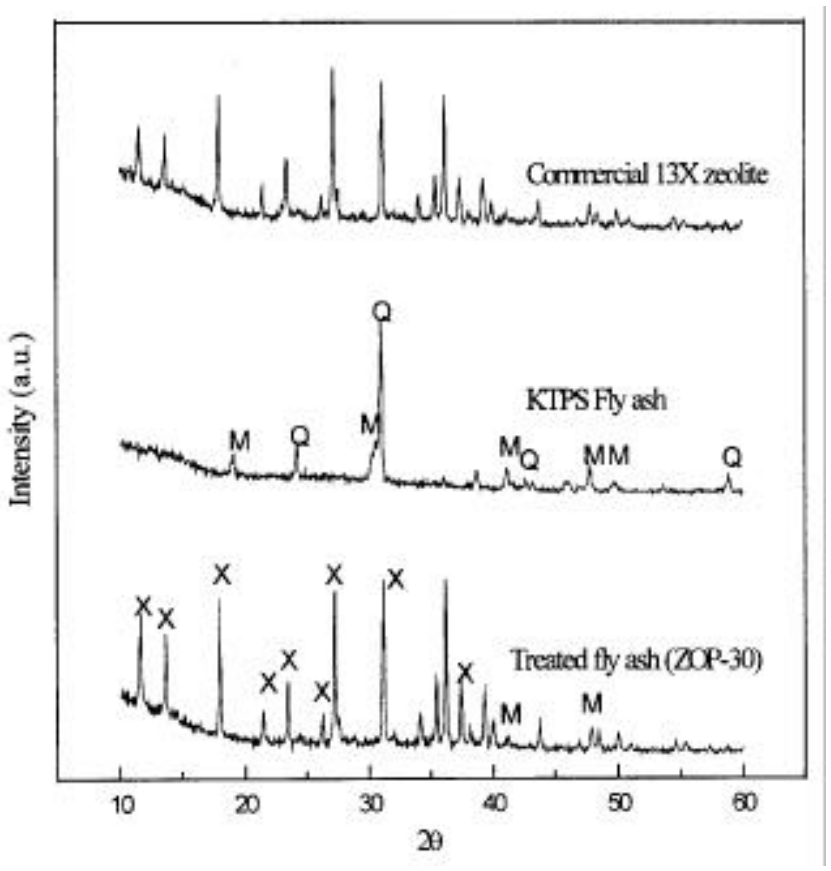

Figure 2. XRD patterns of fly ash, synthesized zeolite (ZOP-30) and commercial $13 \mathrm{X}$ zeolite.

INDEX to the POWDER DIFFRACTION FILE (1967) and data files compiled in the book by Szostak (1976). The diffractograms show that the original crystalline phases of fly ash, quartz and mullite, are mostly absent in the zeolitic materials after reaction. The XRD patterns of the treated fly ash (KTPS fly ash is taken as the representative, figure 2) exactly matched with that of the X-type zeolite (Charnell 1971).

The scanning electron micrographs (SEM) of the original fly ash, treated fly ash (synthesized zeolite) and commercial zeolites are shown in figure 3 . The absence of the spherical particles in treated fly ash (as evident from the SEM) indicates high conversion of fly ash to crystalline zeolite on hydrothermal treatment. The crystal structure of the synthesized zeolite was determined to be distorted octahedra (Charnell 1971; Bogomolov and Petranovsky 1986). 


\subsection{Structural feature from infrared spectroscopy}

Although X-ray powder diffraction data and adsorption measurements are the widely used techniques for identification of zeolite structure and types, other techniques also give useful structural information as well. Infrared (IR)
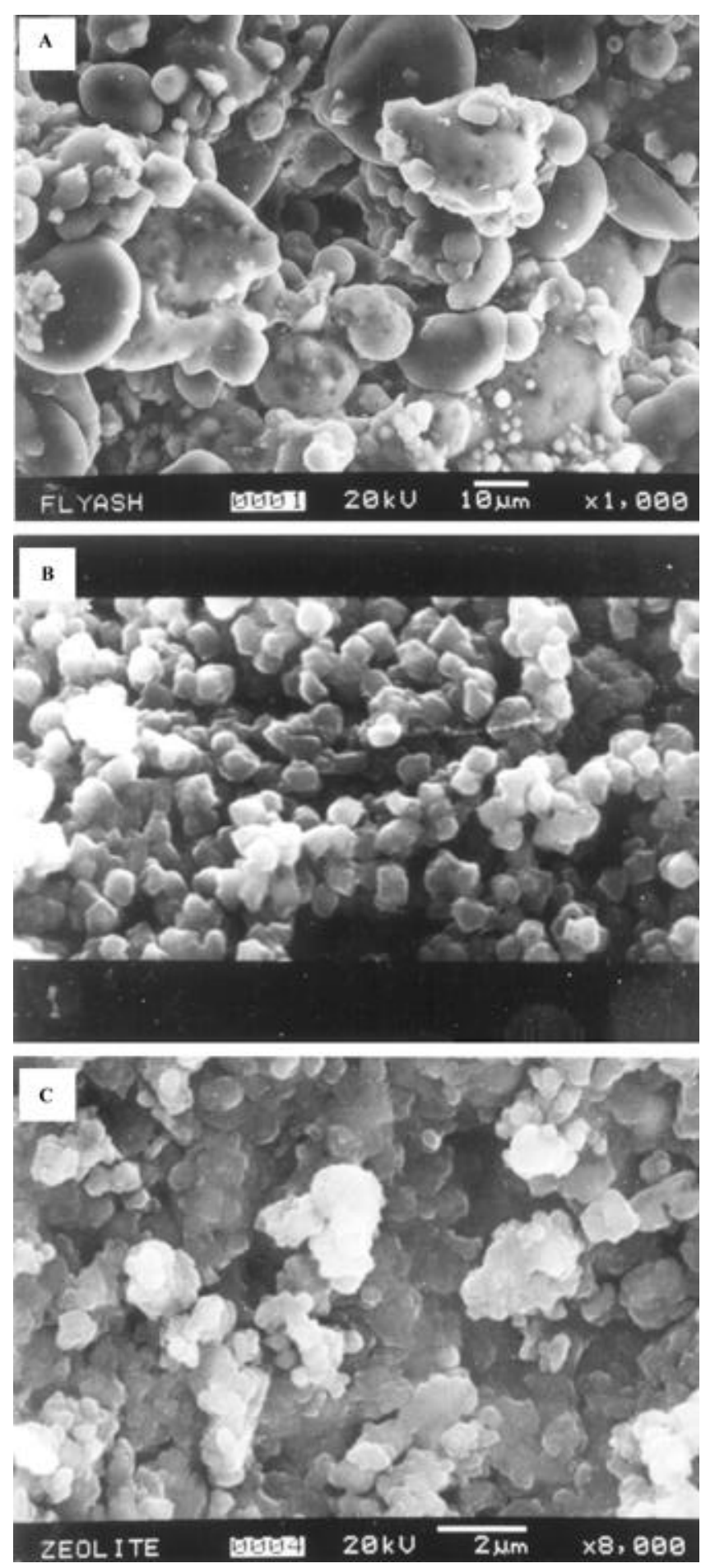

Figure 3. Scanning electron micrographs of (A) fly ash, (B) synthesized zeolite (ZOP-30), and (C) commercial 13X zeolite. spectroscopy can yield information concerning structural details of the material. In general, the IR spectrum can be split into two groups of vibrations: (i) internal vibrations of framework $\mathrm{TO}_{4}$ units, which are insensitive to the structural vibrations; and (ii) vibrations related to the external linkage of the $\mathrm{TO}_{4}$ units in the structures. The latter is sensitive to structural vibrations (Szostak 1976). In general, each zeolite has a characteristic infrared pattern. However, some common features are observed, which include the asymmetric and symmetric stretch, double ring vibrations, $\mathrm{T}-\mathrm{O}$ bending modes, and possibly pore opening modes. The frequency regions where different kinds of vibrations are located in zeolites are summarized in table 3.

The IR spectra of the original fly ash and treated fly ash are shown in figure 4. The two most intense bands for zeolites usually occur at $860-1230 \mathrm{~cm}^{-1}$ and $420-500 \mathrm{~cm}^{-1}$, which are shown more clearly in figure 5 . The first is assigned to an asymmetric stretching mode and the second one to a bending mode of the $\mathrm{T}-\mathrm{O}$ bond. All these bands are more or less dependent on the crystal structure. The midinfrared region of the spectrum contains the fundamental framework vibration of $\mathrm{Si}(\mathrm{Al}) \mathrm{O}_{4}$ groupings. The IR spectral data for $\mathrm{Na}-\mathrm{X}$ type zeolites from the literature (Flanigen et al 1971) and that of the synthesized zeolite are presented in table 4 . The absorbance band in between the wave numbers $980-1320 \mathrm{~cm}^{-1}$ in the IR spectrum of fly ash and treated fly ash represents the presence of substituted $\mathrm{Al}$ atoms in the tetrahedral forms of silica frameworks. All these observations confirm the formation of $\mathrm{X}$-type zeolites on alkali and hydrothermal treatments of fly ash.

\subsection{Alkali requirement for fusion of fly ash}

Alkali fusion is a conventional method for chemical analysis to decompose materials containing silicon and/or aluminum. The sodium hydroxide present in the reaction mixture acts as an activator during fusion to form soluble silicate and aluminate salts, which further takes part in zeolite formation during hydrothermal process. $\mathrm{Na}^{+}$cation also plays an important role in zeolitization. Sodium ions are known to stabilize the sub-building units (specially

Table 3. Zeolite IR assignments (common for all zeolites).

\begin{tabular}{lc}
\hline Internal tetrahedral: & \\
Asymmetric stretch & $1250-950$ \\
Symmetric stretch & $720-650$ \\
T-O bend & $420-500$ \\
& \\
External linkage: & $650-500$ \\
Double ring & $300-420$ \\
Pore opening & $750-820$ \\
Symmetric stretch & $1050-1150$ (Sharp) \\
Asymmetric stretch & \\
\hline
\end{tabular}


six member ring) of zeolite frameworks and usually are required for zeolite synthesis under hydrothermal conditions. The effects of $\mathrm{NaOH}$ to fly ash ratio on $\mathrm{SiO}_{2} / \mathrm{Al}_{2} \mathrm{O}_{3}$ as well as on $\mathrm{Na} / \mathrm{Al}$ ratio of the prepared zeolite were studied by varying the ratio from $1 \cdot 0-1 \cdot 5$. It can be seen from figure 6 that the $\mathrm{SiO}_{2} / \mathrm{Al}_{2} \mathrm{O}_{3}(w / w)$ ratio in the bulk phase changed from $1.68-1.98$ as the $\mathrm{NaOH} /$ fly ash ratio was varied from 1.0-1.2, attained a maxima at $1 \cdot 2$ and then started to fall. The sodium to aluminum (atomic) ratio of the treated ash was also found to increase with the increase in $\mathrm{NaOH}$ content of the mixture during fusion as shown in figure 6 . The higher the sodium contents in the reactant mixture during fusion, the higher is the production of water-soluble sodium silicates. Increased formation of sodium silicates again enhances the yield of zeolitic materials produced in subsequent stages.

Crystallization of the zeolitic materials occurs through nucleation reaction and crystal growth. Nucleation again depends upon the alkalinity. Thus, crystallinity of the resultant products is a function of the alkalinity of the reaction mixture. The effect of $\mathrm{NaOH} / \mathrm{fly}$ ash ratio on crystallinity is shown in figure 7. Crystallinity of synthesized zeolite increases with increase in $\mathrm{NaOH} /$ fly ash ratio up to a certain value after which it shows a decreasing trend. As mentioned earlier, alkali present in the fusion mixture reacts with the silica and alumina present in the fly ash and form silicate and aluminate salts. The mineralogical study indicated the presence of mullite and quartz as major reactive phases during zeolite synthesis from fly ash after alkali activation. Hematite $\left(\mathrm{Fe}_{2} \mathrm{O}_{3}\right)$ was not affected by the activation. However, separation of iron oxides prior to zeolite synthesis resulted in an increase in conversion efficiency as described in the acid treatment section. Silicate anions react readily with $\mathrm{Al}$ (III) precursors to form aluminosilicate compounds. In alkaline solutions, aluminum gives negatively charged tetrahedral $\left[\mathrm{Al}(\mathrm{OH})_{4}\right]^{-}$spe-

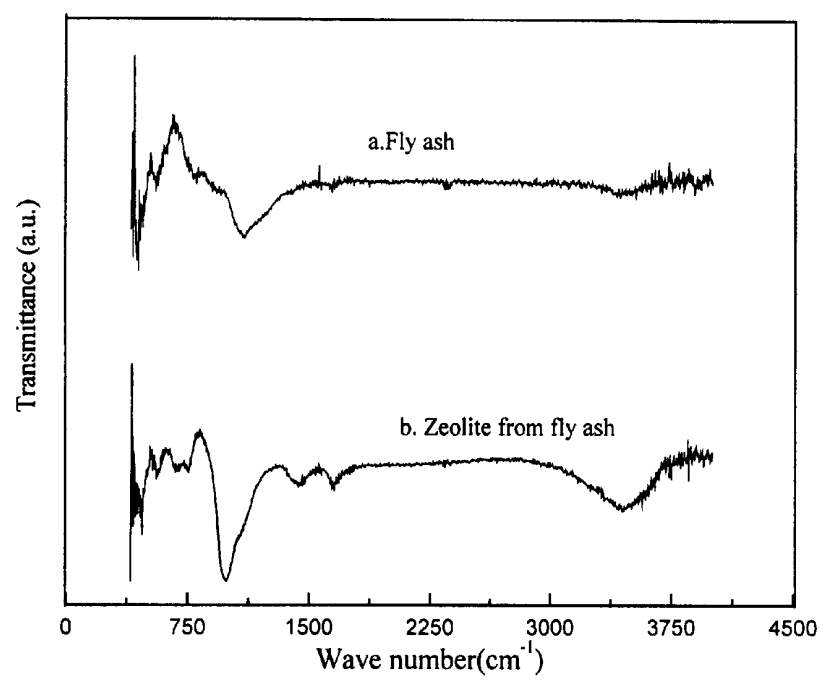

Figure 4. IR spectra of fly ash and zeolite from fly ash (ZOP30). cies, a structure consistent with its incorporation into zeolite framework during hydrothermal treatment. The general reaction scheme describing the zeolite synthesis process is as follows:

$$
\begin{aligned}
& \mathrm{NaOH}+x \mathrm{Al}_{2} \mathrm{O}_{3} \cdot y \mathrm{SiO}_{2} \stackrel{\text { Fusion }}{\longrightarrow} \mathrm{Na}_{2} \mathrm{SiO}_{3}+\mathrm{Na}_{2} \mathrm{AlO}_{2} \\
& \mathrm{NaOH}(\mathrm{aq})+\mathrm{Na}_{2} \mathrm{Al}(\mathrm{OH})_{4}(\mathrm{aq})+\mathrm{Na}_{2} \mathrm{SiO}_{3}(\mathrm{aq}) \stackrel{\text { room-temperature }}{\longrightarrow} \\
& {\left[\mathrm{Na}_{x}\left(\mathrm{AlO}_{2}\right)_{y}\left(\mathrm{SiO}_{2}\right)_{z} \cdot \mathrm{NaOH} \cdot \mathrm{H}_{2} \mathrm{O}\right](\mathrm{gel}) \stackrel{323-623 \mathrm{~K}}{\longrightarrow}} \\
& \quad \mathrm{Na}_{p}\left[\left(\mathrm{AlO}_{2}\right)_{p}\left(\mathrm{SiO}_{2}\right)_{q}\right] \cdot h \mathrm{H}_{2} \mathrm{O} \text { (crystal in suspension) }
\end{aligned}
$$

\subsection{Effect of fusion temperature}

The properties of synthesized zeolitic materials are also affected by fusion temperature (FT). The effect of fusion temperature on $\mathrm{SiO}_{2} / \mathrm{Al}_{2} \mathrm{O}_{3}$ ratio was studied in the temperature range 773-923 K. Figure 8 shows the variation of $\mathrm{SiO}_{2} / \mathrm{Al}_{2} \mathrm{O}_{3}$ ratio with fusion temperature. As seen from this figure, the ratio first increases with fusion temperature, attains the maximum at around $823 \mathrm{~K}$ and then decreases. During fusion, the silica and alumina present in the fly ash react with the alkali and form $\mathrm{Na}$-salts soluble in water.

The crystallinity was also found to change with fusion temperature and the maximum value was obtained at $823 \mathrm{~K}$ as shown in figure 8 . With increase in temperature beyond this point, the crystallinity of the synthesized zeolite was found to decrease.

\subsection{Effect of aging time}

The influence of aging at room temperature on the characteristics of the synthesized zeolite was investigated in

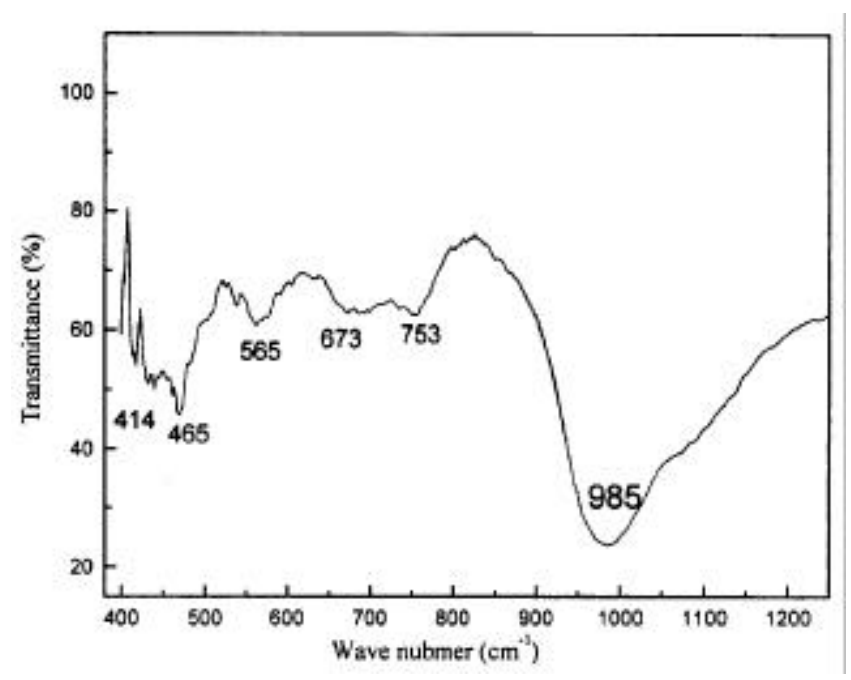

Figure 5. IR spectra of synthesized zeolite in $1250-400 \mathrm{~cm}^{-1}$ wave number region. 
Table 4. Infrared spectral data for Zeolite X.

\begin{tabular}{|c|c|c|}
\hline$\overbrace{\text { Parameter } \downarrow}^{\text {Wave number }}$ & Synthesized zeolite & $\mathrm{Na}-\mathrm{X}$ (Flanigen et al 1971) \\
\hline Double ring & $565 \mathrm{mb}$ & $560 \mathrm{~m}$ \\
\hline Asymmetric stretching & $1061 \mathrm{msh} 980 \mathrm{~s} \quad 753 \mathrm{w}$ & $1060 \mathrm{msh} \quad 971 \mathrm{~s} \quad 746 \mathrm{~m}$ \\
\hline Symmetric stretching & 670 w 690 wsh & $668 \mathrm{~m} 690 \mathrm{wsh}$ \\
\hline $\mathrm{T}-\mathrm{O}$ bending & $470 \mathrm{ws}$ & $458 \mathrm{~ms}$ \\
\hline Pore opening & $414 \mathrm{~ms}$ & 406 w $365 \mathrm{~m}$ \\
\hline
\end{tabular}

$\mathrm{s}=$ strong; $\mathrm{ms}=$ medium strong $; \mathrm{m}=$ medium $; \mathrm{mw}=$ medium weak $; \mathrm{sh}=$ shoulder $\mathrm{b}=\mathrm{broad} ;$ $\mathrm{w}=$ weak.

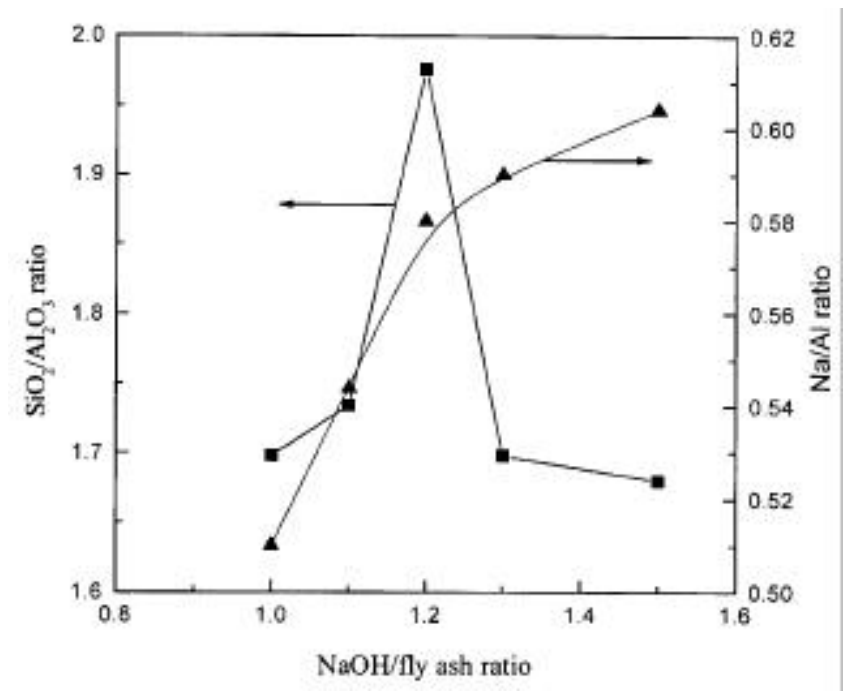

Figure 6. Effect of $\mathrm{NaOH}$ content of reaction mixture on $\mathrm{SiO}_{2} / \mathrm{Al}_{2} \mathrm{O}_{3}$ and $\mathrm{Na} / \mathrm{Al}$ ratios of synthesized zeolite (Conditions: aging time, $18 \mathrm{~h}$; hydrothermal treatment time, $6 \mathrm{~h}$; fusion temperature, $823 \mathrm{~K})$.

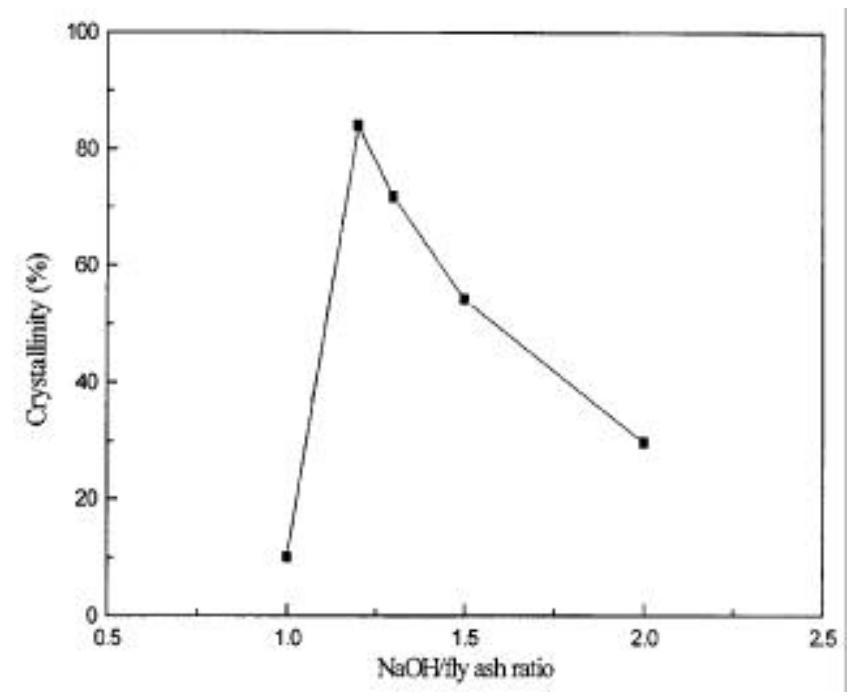

Figure 7. Effect of $\mathrm{NaOH} / \mathrm{fly}$ ash ratio on crystallinity of synthesized zeolite (Conditions: aging time, $18 \mathrm{~h}$; hydrothermal treatment time, $6 \mathrm{~h}$; fusion temperature, $823 \mathrm{~K}$ ). the present work. The aging is related to the development of crystal nuclei. It is observed from previous studies that the aging can considerably reduce the reaction time for crystallization at elevated temperatures (Tatič and Držaj 1985).

The effects of aging time on $\mathrm{SiO}_{2} / \mathrm{Al}_{2} \mathrm{O}_{3}$ ratio as well as on crystallinity of the synthesized zeolite were shown in figure 9. As seen from this figure, the $\mathrm{SiO}_{2} / \mathrm{Al}_{2} \mathrm{O}_{3}$ ratio of the zeolite increases first and then decreases after attaining a maximum of 1.72 for an aging time of $18 \mathrm{~h}$. The crystallinity of the synthesized zeolite, however, increases with aging time up to about $24 \mathrm{~h}$ and then becomes almost independent of it as observed from the same figure. Therefore, an aging time was optimized at $18 \mathrm{~h}$ to get highly crystalline zeolite with high silica/alumina ratio.

\subsection{Effect of hydrothermal treatment time}

During hydrothermal treatment, the aluminosilicate salts crystallize as various zeolitic materials. Previous studies reported that zeolites could be synthesized at any temperature in the range $333-573 \mathrm{~K}$. The faujasite like zeolites (types $\mathrm{X}$ and $\mathrm{Y}$ ) nucleate and crystallize more readily at lower temperature than those having more complicated structure such as mordenite. The recommended crystallization temperature, which gives a reasonable rate and well developed crystals, is about $373 \mathrm{~K}$ (Breck 1974). In the present study, the hydrothermal treatment temperature was kept at $363 \mathrm{~K}$ for the above-mentioned reasons. Hydrothermal treatment time was found to influence the surface area of the synthesized zeolite as shown in figure 10 . From the figure, it is clear that the surface area of the prepared zeolite increases gradually with increase in hydrothermal treatment time up to $6 \mathrm{~h}$ and then decreases. Hydrothermal treatment time was, therefore, optimized at $6 \mathrm{~h}$. In their publication on zeolite synthesis from fly ash, Nugteren et al (1995) reported that there is an incubation period of $3 \mathrm{~h}$ during which the nucleation of zeolites takes place. Following nucleation, the crystallization yield increases progressively up to $24 \mathrm{~h}$. After this second stage, there is only a minor increase of zeolitization with time. 
In the present study, no improvement in the crystal growth was observed after $6 \mathrm{~h}$. This observation is also in good conformity with the findings of Tatič and Držaj (1985). Furthermore, the zeolite $\mathrm{X}$ was found to be transformed to the more stable phillipsite phase when it was kept in contact with its mother liquor for a longer period of time.

\subsection{Effect of acid $(\mathrm{HCl})$ treatment}

Alongwith $\mathrm{SiO}_{2}$ and $\mathrm{Al}_{2} \mathrm{O}_{3}$, fly ash contains several other components that are undesirable in synthesized zeolites. Some of these components act as poison during catalytic

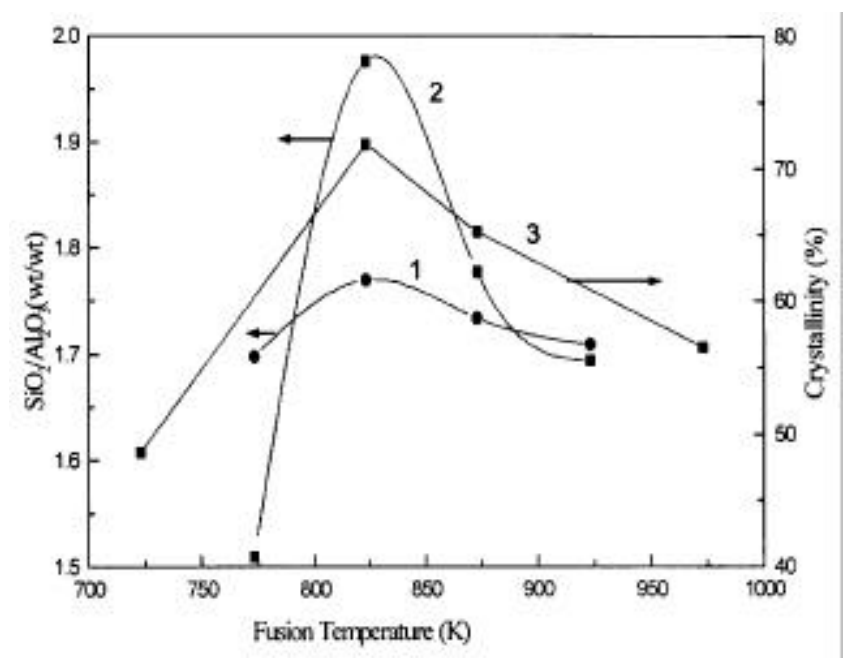

Figure 8. Effect of fusion temperature on $\mathrm{SiO}_{2} / \mathrm{Al}_{2} \mathrm{O}_{3}$ ratio and crystallinity of synthesized zeolite (Conditions: hydrothermal treatment time, $6 \mathrm{~h}$; (1) NaOH/fly ash ratio, 1.0; aging time, $18 \mathrm{~h}$; (2) $\mathrm{NaOH} /$ fly ash ratio, 1.3 ; aging time, $18 \mathrm{~h}$; (3) $\mathrm{NaOH} /$ fly ash ratio, $1 \cdot 3$; aging time, $12 \mathrm{~h}$ ).

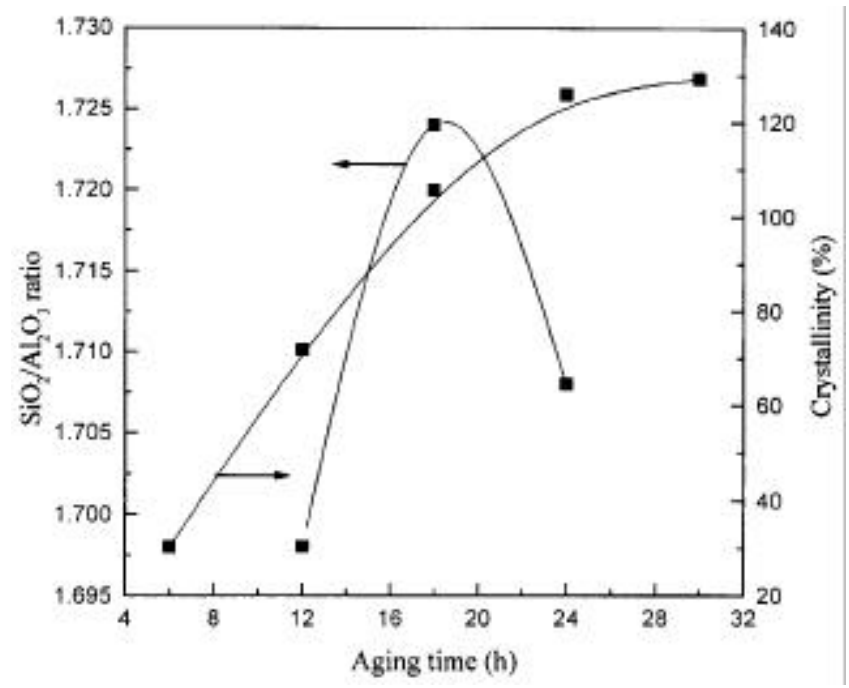

Figure 9. Effect of aging time on $\mathrm{SiO}_{2} / \mathrm{Al}_{2} \mathrm{O}_{3}$ ratio and crystallinity of synthesized zeolite (Conditions: $\mathrm{NaOH} /$ fly ash ratio, $1 \cdot 3$; fusion temperature, $823 \mathrm{~K}$; hydrothermal treatment time, $6 \mathrm{~h}$ ). applications of zeolites. Some of these unwanted materials could be removed by acid treatment. In the present study, $\mathrm{HCl}$ was used to reduce the concentration of iron and alkali oxides present in fly ash, which were located mainly in the outer part of the ash particles (Natush and Taylor 1980) and also to leach some amount of $\mathrm{Al}_{2} \mathrm{O}_{3}$. Thus, it helped in increasing the $\mathrm{SiO}_{2}$ content of the reaction mixture. On acid treatment, iron oxide present in the original fly ash was removed to some extent.

Addition of Na-silicate to the fly ash before hydrothermal treatment is known to increase the $\mathrm{SiO}_{2} / \mathrm{Al}_{2} \mathrm{O}_{3}$ ratio, but no improvement was observed in our experiment on addition of Na-silicate (table 5).

\subsection{Thermal stability of the prepared zeolite}

Crystalline zeolites are more resistive to heat than amorphous materials, the main reason being the geometrical structure of the crystalline framework. However, the effects of silica/alumina ratio and level of cations exchange on thermal stability also cannot be denied. The commercial zeolites having high $\mathrm{SiO}_{2} / \mathrm{Al}_{2} \mathrm{O}_{3}$ ratio can resist much higher temperature. The zeolite presently prepared was observed to lose its crystallinity beyond $973 \mathrm{~K}$ and the crystalline structure was mostly collapsed above $1073 \mathrm{~K}$ (figure 11).

\subsection{Comparative study on fly ashes collected from different sources}

There are more than 80 thermal power plants in India, which use coal from different mines. Usually, the charac-

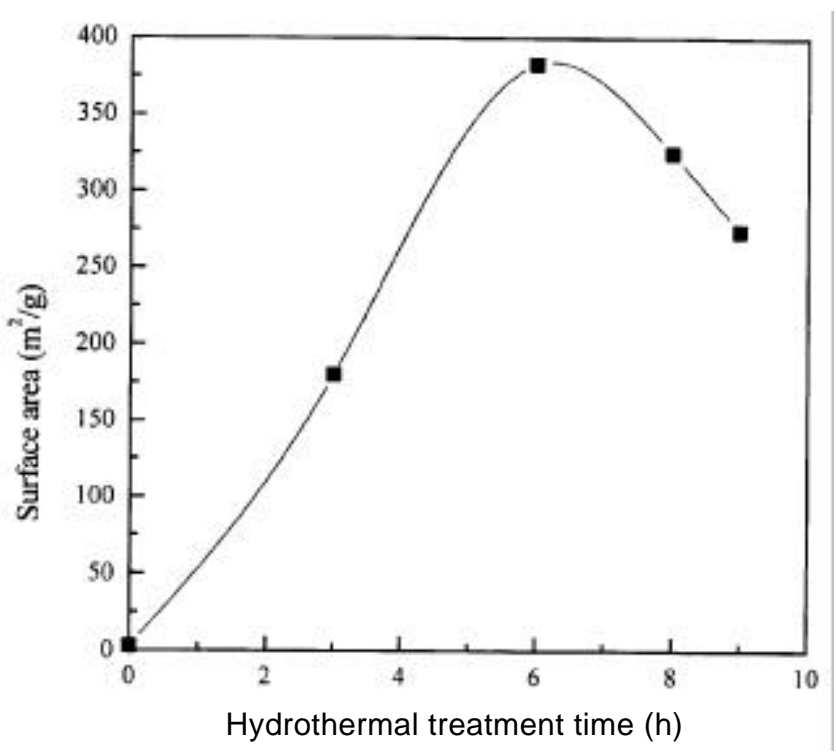

Figure 10. Effect of hydrothermal treatment time on surface area of synthesized zeolite (Conditions: $\mathrm{NaOH} /$ fly ash ratio, 1.3; fusion temperature, $823 \mathrm{~K}$; aging time, $18 \mathrm{~h}$ ). 
Table 5. Variations of $\mathrm{SiO}_{2} / \mathrm{Al}_{2} \mathrm{O}_{3}$ and $\mathrm{Na} / \mathrm{Al}$ ratios of the synthesized zeolite with different treatments.

\begin{tabular}{lcc}
\hline Material & $\mathrm{SiO}_{2} / \mathrm{Al}_{2} \mathrm{O}_{3}$ & $\mathrm{Na} / \mathrm{Al}$ \\
\hline 1. Fly ash $+\mathrm{NaOH}$ & 1.70 & 0.642 \\
2. Fly ash $+\mathrm{Na}$-silicate $+\mathrm{NaOH}$ & 1.44 & 0.803 \\
3. Fly ash treated with $\mathrm{HCl}$ before fusion $+\mathrm{NaOH}$ & 1.82 & 0.250 \\
4. Commercial 13X zeolite & 1.51 & 0.491 \\
\hline
\end{tabular}

Conditions: $\mathrm{NaOH} / \mathrm{fly}$ ash ratio, $1 \cdot 3$; fusion temperature, $550^{\circ} \mathrm{C}$; aging time, $18 \mathrm{~h}$; hydrothermal treatment time, $6 \mathrm{~h}$.

Table 6. Physico-chemical properties of zeolites synthesized from fly ash of different sources.

\begin{tabular}{|c|c|c|c|c|c|c|}
\hline Composition (wt \%) & ZOP-21 & ZOP-30 & ZOP-31 & ZOP-53 & ZOP-57 & Commercial (13X) \\
\hline $\mathrm{SiO}_{2}$ & $50 \cdot 81$ & $47 \cdot 8$ & $48 \cdot 03$ & $42 \cdot 19$ & $40 \cdot 82$ & $48 \cdot 26$ \\
\hline $\mathrm{Al}_{2} \mathrm{O}_{3}$ & 27.97 & $27 \cdot 4$ & $27 \cdot 20$ & 31.66 & $25 \cdot 60$ & $31 \cdot 87$ \\
\hline $\mathrm{Fe}_{2} \mathrm{O}_{3}$ & $2 \cdot 11$ & $2 \cdot 9$ & $3 \cdot 57$ & $5 \cdot 41$ & 1.73 & $3 \cdot 00$ \\
\hline $\mathrm{Na}_{2} \mathrm{O}$ & $13 \cdot 21$ & $17 \cdot 6$ & $15 \cdot 57$ & 8.94 & $15 \cdot 22$ & $15 \cdot 67$ \\
\hline $\mathrm{CaO}$ & $1 \cdot 14$ & 1.0 & 1.47 & $2 \cdot 67$ & $4 \cdot 16$ & $0 \cdot 37$ \\
\hline $\mathrm{K}_{2} \mathrm{O}$ & 0.68 & $0 \cdot 6$ & 0.77 & 0.0 & 0.75 & 0.07 \\
\hline $\mathrm{TiO}_{2}$ & $2 \cdot 54$ & $1 \cdot 4$ & $2 \cdot 12$ & $5 \cdot 15$ & $1 \cdot 24$ & $0 \cdot 08$ \\
\hline $\mathrm{MgO}$ & 0.69 & $0 \cdot 6$ & 0.49 & 0.52 & 0.96 & $0 \cdot 00$ \\
\hline $\mathrm{BaO}$ & $0 \cdot 85$ & $0 \cdot 7$ & 0.78 & $0 \cdot 0$ & $0 \cdot 90$ & $0 \cdot 00$ \\
\hline Surface area $\left(\mathrm{m}^{2} / \mathrm{g}\right)$ & 350 & 383 & 376 & 296 & 320 & 478 \\
\hline Mean particle size $(\mu \mathrm{m})$ & $5 \cdot 35$ & $5 \cdot 69$ & $5 \cdot 60$ & $14 \cdot 15$ & $5 \cdot 20$ & $1 \cdot 57$ \\
\hline Crystallinity (\%) & $75 \cdot 64$ & $125 \cdot 93$ & $84 \cdot 55$ & $30 \cdot 47$ & $40 \cdot 80$ & 100 \\
\hline
\end{tabular}

teristics of the fly ash produced are also varied depending on their sources. Synthesis of zeolites was studied with fly ash samples from three different Indian thermal power plants. Along with other parameters, initial composition of fly ash affects the properties of the end products. As stated earlier, fly ash samples were collected from the KTPS, DTPS and NALCO and zeolites were synthesized from these samples. The synthesis conditions were optimized with respect to the silica/alumina ratio from the detailed study with the KTPS fly ash (ZOP-31). The optimum conditions are: $\mathrm{FT}=823 \mathrm{~K}, \mathrm{NaOH} / \mathrm{fly}$ ash $=1 \cdot 3(w / w)$, aging time $=18 \mathrm{~h}, \mathrm{HTt}=6 \mathrm{~h}, \mathrm{HTT}=363 \mathrm{~K}$. Zeolites were also synthesized from DTPS (ZOP-53) and NALCO (ZOP57) fly ash using the optimum conditions. Physico-chemical properties of these samples were determined applying various techniques as listed in table 6. From the table, it is observed that zeolite synthesized from KTPS fly ash (ZOP-30) is most crystalline and also possesses the maximum surface area. DTPS fly ash contains more iron oxides, which might poison the synthesized zeolitic material for use as catalyst. Crystallinity of ZOP-53 is least compared to the other two. Crystallinity of ZOP-57 is moderate, but presence of $\mathrm{CaO}$ possibly hinders formation of $\mathrm{X}$-type zeolite.

The production cost of the synthesized zeolite was calculated by taking into account the costs of chemicals and utilities for all the steps involved in the process. The cost

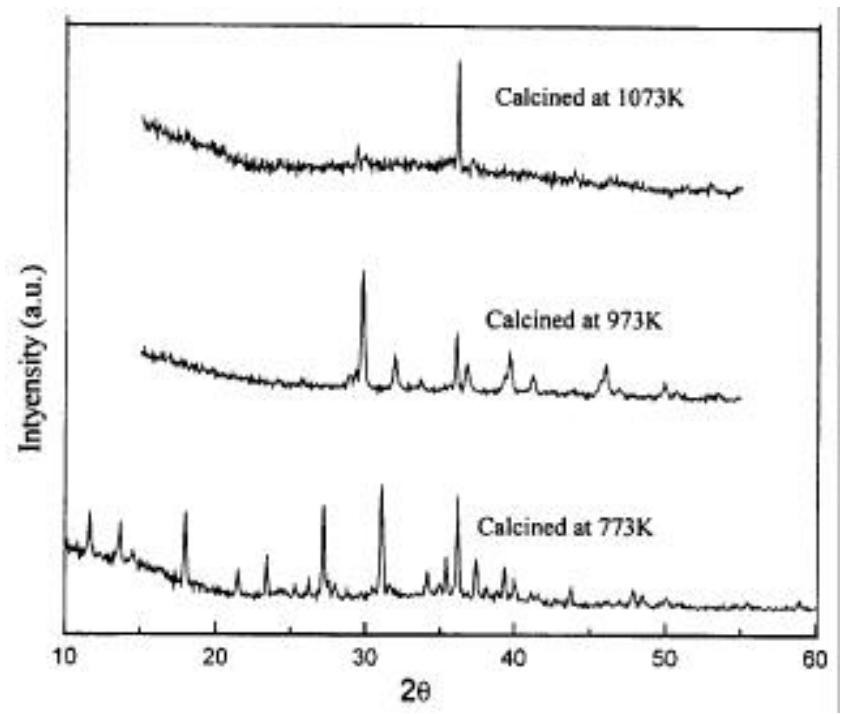

Figure 11. Thermal stability of synthesized zeolite (ZOP-30).

of synthesized zeolite was estimated to be less than onefifth of that of $13 \mathrm{X}$ zeolite available in the market.

\section{Conclusions}

Zeolite of X-type was synthesized from fly ash by alkali fusion followed by hydrothermal treatment. The main 
crystalline phase of fly ash, quartz, could be converted to pure X-type at suitable treatment conditions. The properties of zeolitic material formed strongly depended upon the treatment conditions and concentrations of the raw materials. Zeolites of varying surface area, silica/alumina ratio, and crystallinity were obtained by changing the reaction parameters. The crystallinity of the prepared zeolite was found to change with fusion temperature and a maximum value was obtained at $823 \mathrm{~K}$.

The best quality, in terms of surface area and crystallinity, $\mathrm{Na}-\mathrm{X}$ zeolite was obtained at the following conditions: $\mathrm{NaOH} /$ fly ash ratio, 1.3 ; fusion temperature, $823 \mathrm{~K}$; aging time, $24 \mathrm{~h}$ and $6 \mathrm{~h}$ of hydrothermal treatment. Maximum yield of $\mathrm{Na}-\mathrm{X}$ zeolite was also obtained at the above conditions with distorted octahedral crystal structure, confirmed by XRD patterns and scanning electron micrographs, and FT-IR studies. The cost of synthesized zeolite was estimated to be almost one-fifth of that of commercial $13 \mathrm{X}$ zeolite available in the market. The present result is, therefore, very much useful in opening up a way to synthesize zeolite at low cost with useful applications.

\section{Acknowledgement}

This work is partly supported by the Ministry of Human Resource Development (MHRD), Govt. of India (Grant No. F26-1/2002 TS.V).

\section{References}

Bogomolov J F and Petranovsky V P 1986 Zeolite 6418

Breck D W 1974 Zeolite molecular sieves (New York: John Wiley and Sons)

Chang H L and Shih W H 1998 Ind. Eng. Chem. Res. 3771
Chang H L and Shih W H 2000 Ind. Eng. Chem. Res. 394185

Charnell J F 1971 J. Cryst. Growth 8291

Flanigen E M, Khatami H and Szymanski H A 1971 Advances in Chemistry Series 101 (Washington: American Chemical Society) pp 201-229

Henmi T 1987a Clay Sci. 6277

Henmi T 1987b Soil Sci. Plant Nutr. 33517

Höller H and Wirsching U 1985 Fortschritte der Mineralogie 6321

Lin C F and Hsi H C 1995 Environ. Sci. Technol. 291109

Mondragón F, Rincón F, Seirra L, Escobar J, Ramierez J and Fernández J 1990 Fuel 69263

Natush D F S and Taylor D R 1980 (Environmental effects of western coal combustion: part IV) (Duluth $\mathrm{M} \mathrm{N}$ : Environmental Research Laboratory)

Nugteren H W, Hallman G G and Janssen-Jurkovicova M 1995 Proceedings of international ash utilization symposium (Lexington: University of Kentucky) p. 224

Park M and Choi C J 1995 Clay Sci. 9219

Park M, Choi C L, Lim W T, Kim M C, Choi J and Heo N H 2000 Microporous Mesoporous Mater. 3791

Querol X, Plana F, Alastuey A and Lopez-Soler A 1997a Fuel 76793

Querol X, Alastuey A, Lopez-Soler A, Plana F, Andrews J M, Juan R, Ferrer P and Ruiz C R 1997b Environ. Sci. Technol. 312527

Shigemoto K, Shirakami K, Hirani S and Hayasi H 1992 Nippon Kagaku Kaishi 484

Shigemoto K, Hayasi H and Miyaura K 1993 J. Mater. Sci. 284781

Shih W H and Chang H L 1996 Mater. Lett. 28263

Shin B S, Lee S O and Kook N P 1995 Korean J. Chem. Eng. 12352

Szostak R 1976 Molecular sieves: Principles of synthesis and identification (New York: Van Nostrand Reinhold)

Tatič M and Držaj B 1985 Zeolites (eds) B Drzaj, S Hocevar, S Pejvonik (Amsterdam: Elsevier Science Publishers)

Yang W H A and Kirkpatrick R J 1990 Am. Miner. 751009

Yoshida A and Inoue K 1986 Zeolites 6467 